\title{
Sô no dialeto mineiro: investigando a implementação
}

\section{Sô in the mineiro dialect: investigating the implementation}

Juliana Costa Moreira ${ }^{1}$

https://orcid.org/0000-0003-4329-7142

\begin{abstract}
Resumo: A forma nominal de tratamento senhor, como vocativo, realiza-se também como sô no dialeto mineiro. Neste artigo, pretendemos investigar a implementação de sô a partir de estudos recentes sobre o tratamento senhor e suas diferentes realizações (RAMOS, 2000, 2011; MOURA E RAMOS, 2004; ALKMIM E MOREIRA, 2013) e sobre vocativos (MOREIRA, 2005, 2008), além de pressupostos teóricos-metodológicos sobre mudança linguística (WEIREICH, LABOV \& HERZOG, 1968). Neste artigo propomos continuar a investigação do percurso do item sô. Partimos da hipótese de Moreira \& Alkmim (2013, p.87) de que a posição à direita da oração é favorável à redução da forma senhor, como vocativo.
\end{abstract}

Palavras-chave: Senhor; Sô; Vocativos; Implementação Linguística.

Abstract: The honorific senhor, as vocative, is executed in different ways, such as sinhô, seu and sô. In this paper, we intend to investigate the implementation of sô in the mineiro dialect based on recent studies about honorific senhor and differents realizations (RAMOS, 2000, 2011; MOURA; RAMOS, 2004; ALKMIM AND MOREIRA, 2013) and about vocatives (MOREIRA, 2005, 2008), by utilizing also the theotical referential of Linguistic Change (WEIREICH, LABOV \& HERZOG, 2006). In this paper, we intend to continue the investigation about the way oh the item sô. We start from of the hypothesis of Moreira \& Alkmim (2013, p.87) that the position to the right of the clause favors the reduction of the senhor form, as vocative.

Keywords: Senhor; Sô; Vocatives; Linguistic Implementation.

\footnotetext{
${ }^{1}$ Universidade Federal de Minas Gerais. E-mail: moreira.julianac@gmail.com
} 


\section{Introdução}

Alkmim (2001); Moreira (2005) e Moreira e Alkmim (2013): a forma senhor é muito utilizada como vocativo em construções extraídas de peças teatrais escritas por autores mineiros nos séculos XIX e XX. Seguem-se exemplos:

1 [Voc + Oração]

a. Senhora, já estais sciente dos meus intentos, conforme acabei de ouvir. (RESENDE, 1882, manuscrito).

b. Oh, senhores, custa-me a acreditar em tamanha felicidade. (PAIVA, 1893, manuscrito).

$2 \quad[\mathrm{Or}+\mathrm{Voc}+\mathrm{Or}]$

Eu, Snr ${ }^{\text {es }}$, não sou nenhum vaqueiro, Que viva de guardar alheio gado... (PAIVA, 1893, manuscrito).

3 [Oração + Voc]

Não há mais barreira, senhor. (WERNECK, 1900, p.120).

Em (1a), o vocativo senhora se encontra à esquerda da oração e, em (1b), o termo senhores também se situa à esquerda da oração, precedido pela partícula oh; em (2), o vocativo Snres está situado em posição medial, particularmente, entre o sujeito e o verbo da oração e, em (3), temos o termo senhor, vocativo, à direita da oração, tratando da posição final.

Moreira (2005, p.99), utilizando-se do aparato teórico da Sociolinguística Variacionista, verifica que, ao início do século XIX, a modalidade [Oração + Voc] se apresenta com mais frequência $(57,5 \%)$ em relação às variantes [Voc + Oração] e [Or + Voc + Or], que representaram, respectivamente, $34,1 \%$ e $8,4 \%$.

Ao analisar o uso das variantes em relação ao tempo, verifica-se que a variante [Voc + Oração], que ocorre com mais frequência na $1^{\mathrm{a}}$ metade do século XIX, descende gradativamente ao longo do tempo. Já a variante [Oração + Voc] apresenta um perfil de mudança linguística, uma vez que os resultados da análise apresentam uma porcentagem que passa de $34 \%\left(1^{\text {a }}\right.$ metade do século XIX) para $46,7 \%$, na $2^{\text {a }}$ metade do século XIX, crescendo para $58,2 \%$ na $1^{\text {a }}$ metade do século XX e chegando a 79,6\% na $2^{\mathrm{a}}$ metade do século XX.

No corpus de Moreira (2005), observa-se que a forma nominal de tratamento senhor, como vocativo, realiza-se de diferentes formas, por exemplo sinhô, seu e sô. Moreira (2005) 
registra a realização dessas diferentes formas em corpus constituído por peças teatrais escritas por autores mineiros nos séculos XIX e XX, como ilustrado abaixo:

(1) Não sei, não sinhô, foi um branco que me deu. (PAIVA, 1897, manuscrito).

(2) a. Seu dotô, não há esse que não tenha um podre na vida.

b. Oia, seu dotô, uma lembrança dela. (BRAGA, 1915, manuscrito).

(3) A onça, Sôr Porteiro, a onça que cá está. (PAIVA, 1897, manuscrito).

(4) Ah siô Belchior! é um estirão do Porqueiro até aqui. (RESENDE, 1906, manuscrito).

(5) Tô notando, sô, e aperciando e hei de vortá aqui mais veis... (PAIVA, 1897, manuscrito).

No exemplo (4), temos a realização da forma sinhô, antecedida por não, formando uma resposta negativa; em (5a) e (5b) observa-se que a forma seu ocorre seguida por um nome dotô. À semelhança de seu, as formas sôr, em (6), e siô, em (7), ocorrem seguidas de um nome, como em Sôr Porteiro e siô Belchior. Observa-se também em (7) que a forma siô, em posição inicial, é precedida pela interjeição ah. Já no exemplo (8), a forma sô se realiza ao final da primeira oração do período.

Moreira e Alkmim (2013, p.87) oferecem uma explicação para a emergência de sô e das outras formas reduzidas. Segundo as autoras, a posição em que o vocativo ocorre com maior frequência, à direita da oração, ao final do século $\mathrm{XX}$, corresponde ao ambiente sintático favorável à gramaticalização e consequente redução da forma senhor, de modo que se obtêm a forma reduzida "sô".

Face ao exposto, o nosso objetivo é investigar a implementação de sô, a fim de contribuir para a descrição do percurso da expressão nominal de tratamento senhor. Partimos da hipótese de Moreira e Alkmim (2013) que consideram a posição à direita da oração favorável à ocorrência do item sô, forma reduzida de senhor, utilizando-se dados de intuição e juízos de gramaticalidade de falantes nativos.

Como referencial teórico, utilizamos estudos recentes sobre o tratamento senhor e suas diferentes realizações (RAMOS, 2000, 2011; MOURA, 2004), além de pressupostos teóricos sobre mudança linguística, presentes no arcabouço teórico da Sociolinguística Variacionista (WEINREICH; LABOV; HERZOG, 1968). 
Este artigo se organiza na seguinte sequência: na próxima seção, apresentaremos o referencial teórico utilizado; na seção 2, apresentaremos estudos que contribuem para o estudo da implementação da forma sô no sistema gramatical; na seção 3, a partir da descrição de dados de intuição, continuamos a investigação da implementação, ao explorar os contextos sintáticos em que sô ocorre, além de investigar o estatuto sintático desta forma e, por último, apresentamos as algumas considerações.

\section{Referencial teórico}

\section{$1.1 \mathrm{O}$ percurso de senhor}

Estudos recentes sobre o tratamento senhor e suas diferentes realizações foram desenvolvidos tendo como pressuposto a observação de Ramos (2000) de que tais formas, apesar de serem estabelecidas pela sociedade, sofrem alterações no decorrer do tempo, tanto em relação ao contexto em que são usadas, quanto ao modo como se realizam morfofonologicamente.

Ramos (2000) recompõe o caminho percorrido pela forma senhor, tanto através da estrutura social, quanto da gramática nos séculos XIV a XIX. Etimologicamente, “o item senhor vem do latim senior, seniores, mais velho, mais idoso, comparativo de superioridade de senex, velho", de acordo com a definição de Bueno (1937, apud Ramos 2001, p.2). Esse item adquiriu significado de proprietário, dono absoluto, aquele que tinha autoridade feudal sobre certas pessoas ou propriedades. Além disso, quando senhor passou a ser utilizado correntemente pelo povo significa que esse item já se referia à distância social entre interlocutores, evidenciando um ponto em comum com você.

Para a autora, houve a extensão de sentido do referido item: homem idoso > homem possuidor de bens e pessoas $>$ homens poderosos $>$ homens de respeito. Luz (1959 apud Moura e Ramos, 2004, p. 79) afirma que a partir do século XIX, o pronome vós, ao cair em desuso, deixa em aberto uma lacuna que vem a ser preenchida pelo uso de senhor e suas variantes, indicando respeito. No momento em que as diferentes formas indiretas de tratamento vão atingindo as camadas populares, senhor passa a apresentar um ponto em comum com você: ambas as formas mantêm o tratamento indireto de segunda pessoa, podendo ser usadas sem mencionar o nome do interlocutor. Portanto, são ambas pronominais.

Moura e Ramos (2004) analisam as formas reduzidas do item senhor: sinhô, seu e sô 
como um fenômeno de variação linguística. Conforme as autoras, o item sô, forma reduzida de senhor, na função de vocativo, é atribuído às pessoas independentemente do sexo e da idade. Seguem-se exemplos da forma sô direcionada ao feminino em conversas espontâneas de crianças e adultos.

(9) A filha disse pra mãe: "deix" eu ir sô! (A.S.A., 5 anos)

(10) Entre duas jovens: "Não sô, assim não..." (L.O., 9 anos)

Exemplos de Moura e Ramos (2004, p.35)

Veja-se que nesses casos, a forma não carrega nuance de formalidade, não indica respeito à imagem do interlocutor e, nem mesmo, insinua que aquele é mais velho, além de a forma masculina poder ser utilizada para se dirigir às mulheres.

Sobre a mudança do estatuto gramatical do item senhor, Ramos (2000) pontua que a ocorrência inicialmente à direita do nome como padre senhor e, posteriormente, à esquerda como senhor pai permite supor que seu estatuto seja o de modificador do nome; já a ocorrência do item isolado, presente em momento posterior, permite atribuir-lhe o estatuto de nome.

(11) O Senhor João está aqui?

Exemplo (7) de Moura e Ramos (2004, p.33)

(12) O que é isso, meu Senhor?

Exemplo (8) de Moura e Ramos (2004, p.33)

(13) Minha senhora, assente-se aqui./ Meu senhor, assente-se aqui.

Exemplo (9a) de Moura e Ramos (2004, p.33)

(14) Senhora, assente-se aqui. /Senhor assente-se aqui.

Exemplo (9a) de Moura e Ramos (2004, p.33)

Nos exemplos de (11) a (13), o estatuto gramatical de senhor é o de modificador do nome, ao passo que em (13) e (14), ao termo senhora, é atribuído o estatuto de nome.

Para Moura e Ramos (2004, p.77), o percurso de senhor pode ser descrito como gramaticalização, que ocorre quando se têm alterações sintáticas, semânticas e morfofonéticas 
de um determinado item. Moura e Ramos (2004, p.77) pontuam que é provável que o item sô tenha adquirido o estatuto de pronome. O percurso de nome a pronome é descrito por Ramos (2011, p.70) como explicitado na cline abaixo:

(15) senhor $>\ldots>\operatorname{sinhô}>\ldots>$ sô

Exemplo (1) de Ramos (2011, p.70)

Segundo Lehman (2002, p.35) "nomes podem ser gramaticalizados como pronomes" e a fonte de pronomes de segunda pessoa são geralmente nomes sociais. Conforme salienta Ramos (2011, p.73):

\begin{abstract}
Esse parece ser o caso do item senhor, por ter sido originariamente um título e hoje referir-se ao interlocutor, sendo por isso um pronome de segunda pessoa. Senhor designava inicialmente o filho mais velho de proprietários de terra, não sendo ainda o item senhor usado como forma de tratamento. Posteriormente o título de senhor foi também atribuído a nobre fidalgos, devido à posse de terras como privilégio. Senhor, enquanto título, foi um nome, mais exatamente, uma expressão honorífica. (RAMOS, 2011, p.73).
\end{abstract}

Não obstante, a forma inicial senhor ainda concorre com sô no dialeto mineiro. De acordo com Ramos (2011), senhor e sô são pronomes, sendo o primeiro uma forma homônima de um nome. Possivelmente, essa resistência pode ser atribuída ao estatuto de desprestígio da forma reduzida, pois é reconhecida pelos falantes como marca de dialeto rural e/ou ausência de escolaridade. Geralmente, em processos de mudança linguística, uma forma de um estágio posterior acarreta a exclusão de uma forma de um estágio anterior, tal como no par vossa mercê/você. ${ }^{2}$

\title{
1.2 O problema da implementação
}

Seguindo Weinreich, Labov e Herzog (1968, p.124), consideramos que o processo global da mudança linguística pode envolver estímulos e restrições tanto da sociedade quanto da estrutura da língua. A dificuldade do enigma da implementação é evidente no número de

\footnotetext{
${ }^{2}$ A avaliação social é um fator que pode reverter processos de mudanças, cancelando-os ou tornando-os mais lentos ou acelerados (Weinreich, Labov e Herzog, 2006, p.124)
} 
fatores que influenciam a mudança. Se considerarmos seriamente o postulado de que a mudança linguística é mudança no comportamento social, então não deve nos surpreender que hipóteses preditivas não estejam prontamente disponíveis. Tais considerações não nos devem impedir de analisar tantos casos quanto forem pudermos em todo pormenor para reunir tais respostas numa visão abrangente do processo de mudança. Portanto, o que propomos realizar neste artigo é reunir as informações disponíveis sobre estudos realizados sobre senhor e sô, os quais podem trazer pistas e evidências sobre a implementação da forma reduzida; e com este mesmo intuito, explorar contextos sintáticos em que ocorre com este mesmo intuito.

De acordo com o arcabouço teórico da Sociolinguística Variacionista, uma mudança linguística começa quando um dos muitos traços característicos da variação na fala se difunde através de um subgrupo específico na comunidade de fala. Este traço linguístico, então, assume uma certa significação social - simbolizando os valores sociais associados àquele grupo. Uma vez que a mudança linguística é encaixada na estrutura linguística, é gradualmente generalizada a outros elementos do sistema. Tal generalização não tem nada de instantânea e a mudança na estrutura social da comunidade intervêm normalmente antes que o processo a complete.

Nessa perspectiva, o avanço da mudança linguística rumo a completação pode ser acompanhado de uma elevação no nível de consciência social da mudança e do estabelecimento de um estereótipo social. Como foi dito na seção anterior, a forma inicial senhor ainda coocorre com a forma sô, sendo que, geralmente, em processos de mudança linguística, uma forma de um estágio posterior acarreta a exclusão de uma forma de um estágio anterior, tal como no par vossa mercê/você. No caso do fenômeno analisado aqui, a resistência de senhor parece ser atribuída ao estatuto de desprestígio das formas reduzidas, pois são reconhecidas pelos falantes como marcas de dialeto rural e/ou ausência de escolaridade.

Na seção seguinte, apresentamos informações relevantes, as quais estão presentes no trabalho de Moreira (2008) sobre a ordem do vocativo na oração do Português Brasileiro e no artigo de Ramos (2011), acerca do processo de pronominalização de senhor.

\section{Investigando a implementação}

Como visto, ao investigar uma possível causa para a redução do item senhor em casos em que este corresponde sintaticamente ao vocativo, Moreira e Alkmim (2013, p.87), levantam a hipótese de que a posição à direita da oração é o locus para a gramaticalização e consequente redução do item senhor. Em detalhes, o sintagma que constitui o vocativo, com a mudança de 
posição na oração, da esquerda para a direita, torna-se mais gramatical. Por esta razão, pode ocorrer perda de conteúdo semântico e fônico do item senhor. Desse modo, a posição à direita da oração pode constituir ambiente propício para a ocorrência da forma reduzida.

Uma evidência para esta hipótese é encontrada em Moreira (2008), que estuda a ordem do vocativo na oração, utilizando um corpus constituído por peças de teatro escritas nos séculos XIX e XX. Os resultados obtidos estão expressos na tabela 1, abaixo:

Tabela 1

Taxa de uso das ocorrências de vocativo em função do tempo

\begin{tabular}{|c|c|c|c|c|c|c|c|c|c|c|c|c|c|}
\hline \multirow[t]{2}{*}{ Estruturas } & \multicolumn{3}{|c|}{$T 1$} & \multicolumn{3}{|c|}{$T 2$} & \multicolumn{3}{|c|}{$T 3$} & \multicolumn{3}{|c|}{$T 4$} & \multirow[t]{2}{*}{ Total } \\
\hline & $\mathbf{N}^{\mathbf{0}}$ & $\%$ & PR & $\mathbf{N}^{\mathbf{0}}$ & $\%$ & PR & $\mathbf{N}^{\mathbf{o}}$ & $\%$ & PR & $\mathbf{N}^{\mathbf{0}}$ & $\%$ & PR & \\
\hline$[\mathrm{Voc}+\mathrm{Or}]$ & 160 & $43 /$ & .61 & 114 & 46 & .56 & 131 & 35 & .43 & 106 & 36 & .39 & 511 \\
\hline$[\mathrm{Or}+\mathrm{Voc}]$ & 209 & 57 & .38 & 133 & 54 & .43 & 245 & 65 & .57 & 189 & 64 & .60 & 776 \\
\hline Total & 369 & 100 & - & 247 & 100 & - & 376 & 100 & - & 295 & 100 & - & 1287 \\
\hline
\end{tabular}

MOREIRA (2008, p. 60)

Observe-se, na primeira metade do século XIX (T1), o vocativo é utilizado com mais frequência em posição inicial (.61) e, no século XX, o índice de ocorrência do vocativo nessa posição decresce e o que se obtém na última metade do século XX (T4) é o peso relativo de .39. Por outro lado, o vocativo em posição final (à direita da oração) é menos frequente ao início do século XIX (T1), apresentando o peso relativo de .38; e se torna mais recorrente ao final do século XX (T4), sendo que o peso relativo apresentado é de .60. O perfil descrito configura um processo de mudança de ordem do vocativo na oração do Português Brasileiro. ${ }^{3}$

Após a identificação deste processo de mudança, Moreira (2008) investiga os fatores linguísticos que podem estar levando a mudança à frente no Português Brasileiro, quais sejam: (i) contexto sintático em que o vocativo está inserido, (ii) modo verbal, participação do vocativo no evento, (iii) itens lexicais que correspondem sintaticamente ao vocativo, (iv) descrição da estrutura sintática do SN vocativo.

Ao detalhar um desses fatores, qual seja, itens lexicais que correspondem sintaticamente ao vocativo, observa-se o peso relativo consideravelmente alto do vocativo, em

\footnotetext{
${ }^{3}$ Esses resultados foram obtidos a partir da submissão dos dados ao Programa Goldvarb 2001.
} 
posição final, quando corresponde a um apelido (.79), a uma expressão nominal de tratamento (.69) e quando se trata de um epíteto (.57), conforme demonstra a Tabela 2, abaixo:

Tabela 2

Taxa de uso da construção [Or + Voc] em função da natureza do material que compõe o vocativo

\begin{tabular}{lccc}
\hline Fatores & $N^{\boldsymbol{o}}$ de & Porcentagem & Pesos Relativos \\
& Ocorrências/ Total & \\
\hline Nome próprio & $356 / 665$ & $53 \%$ & .39 \\
Parentesco & $97 / 164$ & $59 \%$ & .49 \\
Profissional & $30 / 49$ & $61 \%$ & .51 \\
Epíteto & $83 / 117$ & $70 \%$ & .69 \\
Expr. Nom. De trat. & $204 / 285$ & $71 \%$ & .79 \\
Apelido & $6 / 7$ & $85 \%$ & \\
\hline
\end{tabular}

Há de se considerar que é baixo o número de apelidos no total do corpus: há apenas sete construções em que o vocativo corresponde a um apelido, as quais se encontram na peça "Dois perdidos numa noite suja", de Plínio Marcos, obra em que se observa uma linguagem bem coloquial. Esse resultado é plausível, pois em contextos em que não se tem conhecimento do nome de alguém, um pronome, uma expressão nominal de tratamento ou vocativo profissional, por exemplo podem ser utilizados, uma vez que são mais genéricos do que aqueles representados morfofonologicamente por um nome próprio.

Portanto, conclui-se que o índice mais elevado de vocativos em posição final é correspondente a expressões nominais de tratamento, como senhor ou senhora. Esse resultado indica que o alto índice de ocorrência da expressão nominal de tratamento senhor à direita da oração, em posição final, é um dos fatores que impulsionam a mudança de posição do vocativo da esquerda para a direita no Português Brasileiro e, por extensão, pode ter favorecido a redução dessa forma e a obtenção de sô, dentre outras variantes.

Uma segunda evidência a favor da hipótese elaborada por Alkmim e Moreira (2013) é fornecida por Ramos (2011) a partir da análise três corpora, um diacrônico e dois sincrônicos. 
O primeiro corpus analisado é o mesmo do que discorremos acima e, portanto, constituído por diálogos de peças teatrais escritas por autores brasileiros nos séculos XIX e XX. ${ }^{4}$ A Tabela 3, a seguir, apresenta o número e a percentagem de ocorrências deste item conforme o tipo de sintagma na posição de vocativo, se isolado, como em (16) ou se precedido ou seguido por algum material, como em (17), abaixo:

(16) Não falemos mais nisso, senhor (Séc. XIX)

(17) São modos de julgar, meu senhor; nem todos enxergam o que olham (Séc. XX)

Tabela 3

Ocorrências de senhor em vocativos em dois períodos de tempo

\begin{tabular}{|c|c|c|}
\hline Vocativo & Séc. $\boldsymbol{X I X}$ & Séc. $\boldsymbol{X X}$ \\
\hline Senhor & $58 / 63 \%$ & $56 / 76 \%$ \\
$(\mathbf{X})$ senhor $(\mid \mathbf{X})$ & $34 / 37 \%$ & $17 / 24 \%$ \\
\hline Total & $92 / 100 \%$ & $73 / 100 \%$ \\
\hline
\end{tabular}

RAMOS (2011, p. 77)

Para este levantamento foram considerados indistintamente os vocativos à direita, à esquerda ou mediais na sentença. Cabe mencionar que não foram registradas ocorrências foneticamente reduzidas nesse corpus.

O segundo corpus analisado por Ramos (2011) é constituído por diálogos em balcão de atendimento de órgão público (BATISTA, 2008), representativo da língua falada do século XXI.

Nesse corpus, são documentadas formas plenas e fonologicamente reduzidas, como demonstra a Tabela 4, a seguir:

${ }^{4}$ O corpus referido foi cedido por Moreira (2008). 
Tabela 4

Ocorrências das formas plenas e reduzidas no século XXI

\begin{tabular}{|l|c|}
\hline Formas & Séc. $\boldsymbol{X X I}$ \\
\hline o senhor & $185(94,8 \%)$ \\
senhor X & - \\
sô & - \\
\hline Total & $10(5,2 \%)$ \\
\hline
\end{tabular}

RAMOS (2011, p. 77)

De acordo com a Tabela 4, nesse corpus, não há ocorrências da forma plena em função de vocativo e, ainda, que as 10 ocorrências da forma reduzida se deram em função de vocativo. Seguem-se exemplos da forma sô em função de vocativo:

(18) Deus abençoa... tô sem dinheiro, sô.

(19) (...) por que lá é o seguinte, sô, (...)

(20) O negócio tá bravo, sô (...)

$$
\text { Exemplos (11), (12) e (13) de Ramos (2011, p.78) }
$$

O fato de observar somente formas reduzidas em função de vocativo nesse corpus leva a crer que a redução da forma senhor ocorreu especificamente ao desempenhar esta função. Como acentua Ramos (2011), se tivermos em conta que o vocativo constitui o locus em que nomes ocorrem sem determinante, Moreira \& Alkmim (2013, p.87), ao chamar atenção para uma configuração da sentença [Oração + Voc], acabam por ressaltar uma função sintática relevante. Nesse sentido, a ocorrência de senhor, como vocativo à esquerda, à direita ou no meio da oração teria sido o gatilho para a pronominalização de senhor.

De acordo com Ramos (op. cit), a pronominalização se deu ao final da oração e depois o seu uso foi expandido para outras posições disponíveis para o vocativo. Esse processo se desenvolveu nos últimos dois séculos no português e a ocorrência do item na posição de 
vocativo favoreceu a reanálise sintagma nominal > núcleo nominal, chamando a atenção para a importância dos vocativos no processo de pronominalização.

O terceiro corpus analisado pela autora é constituído por entrevistas sociolinguísticas (MOTA, 2011), cujos informantes são naturais de Lontra (MG). Neste corpus, foi identificado um tipo de ocorrência que não foi registrado nos diálogos em balcão de atendimento: a ocorrência de "sô" em posição argumental, desacompanhada de qualquer outro tipo de material. Em (21) e (22), a seguir, apresentamos esse tipo de exemplo:

(21) E as coisa que sô planta na roça sô traz para vender em Lontra?

Exemplo (14) de Ramos (2011, p.79)

(22) De que matéria, sô sabe?

$$
\text { Exemplo (15) de Ramos (2011, p.79) }
$$

Esse tipo de ocorrência de senhor é semelhante à do pronome você na posição de sujeito. O que se observa é, portanto, a variação de senhor e sô em posição argumental. Esses exemplos demonstram a expansão dos ambientes sintáticos em que o item sô ocorre: da ocorrência de sô, como vocativo, à direita da oração à ocorrência em posição argumental.

Recapitulando o que foi visto nesta seção, a partir dos estudos citados, os quais evidenciam que a posição à direita da oração é o locus da redução de senhor:

(i) foi demonstrado que é alto o índice de ocorrência de senhor como vocativo ao longo dos séculos XIX e XX, visto que no estudo de Moreira (2008) foi evidenciado que o material que mais ocorre na função de vocativo são as expressões nominais de tratamento, a saber, senhor(es) e senhora(s);

(ii) utilizando o mesmo corpus, Ramos (2011) também observa que é crescente o número de ocorrências de senhor, isoladamente no vocativo, independentemente da posição sentencial;

(iii) como observado por Ramos (2011), a alta frequência de senhor é comparável à do pronome você, portanto, comparável à de um pronome;

(iv) no eixo temporal, o surgimento de sô é posterior ao surgimento de senhor;

(v) foi confirmada a hipótese de Alkmim e Moreira (2013, p.87) de que a redução da forma senhor ocorre inicialmente na posição de vocativo. O fato de essa função 
permitir a ocorrência de sintagmas nominais sem determinante certamente favoreceu a redução da forma senhor.

Como veremos na próxima seção, há ainda um tipo construção, contendo o item sô, que apresenta um comportamento sintático diferente, à medida que não ocorre isoladamente, precisa ser licenciado por um constituinte à esquerda. No intuito de descrever diferentes contextos sintáticos contendo sô que a forma reduzida contextos sintáticos em que sô ocorre, exploraremos, a seguir, dados de intuição do dialeto mineiro.

\section{Sô e o contexto sintático do dialeto mineiro}

Utilizando dados de intuição e juízos de gramaticalidade de falantes do dialeto mineiro, é possível observar que é natural a ocorrência da partícula sô à direita da oração:

(23) a. Pára com isso, sô.

b. ? Pára com isso,(\#) ô sô.

c. ?Pára com isso, (\#) uai sô.

Há também a possibilidade de uma partícula de chamamento indireto, como $\hat{O}$, ou uma interjeição, como Uai ocorrer ao início da oração, ao passo que a partícula vocativa sô ocorre ao final da oração, como em (24 a) e (24b), abaixo, respectivamente ${ }^{5}$ :

(24) a. Ô, pára com isso, sô.

b. Uai, pára com isso, sô.

\footnotetext{
${ }^{5}$ Seguindo Hill (2014), Moreira (2017, p.68) difere as interjeições propriamente ditas das partículas de chamamento indireto. As partículas de chamamento indireto atuam como chamamento ou cumprimento. Segundo a autora são partículas de chamamento indireto no português, as interjeições $E i, O h$. Ah etc. e outras expressões, como: ok, obrigado, olá, etc. Interjeições como "Nossa", "Ai" e "Ui", por exemplo, não estão incluídas neste grupo por serem considerados constituintes exclamativos.
} 
Observe-se que na resposta em (25), abaixo, a forma sô está alocada no interior da oração, mais especificamente, entre o sujeito e o predicado.

(25) A - Cadê os prego que eu deixei aqui?

B - Os prego, sô, sei cadê não.

É possível a ocorrência da partícula sô, em posição inicial, se houver precedência de interjeição ou de partícula de chamamento direto:

(26) a. Uai sô, o negócio tá feio.

b. Ô sô, o negócio tá feio.

c. * Sô, o negócio tá feio.

Em (26a), a forma sô é precedida pela interjeição uai, enquanto que em (26b) é a partícula de chamamento direto Ô que a precede. Por sua vez, a construção em (18c) é agramatical, uma vez que não há nenhum item lexical à esquerda da forma sô.

Identificamos uma relação de dependência entre partículas vocativas e interjeições ou partículas de chamamento indireto em posição inicial (Uai, sô...; Ô sô....). Esta relação é, provavelmente, oriunda do fato de as partículas serem formas reduzidas, resultantes de um processo de pronominalização. Diante dessa observação levantamos a hipótese de que a forma sô, como vocativo, em posição inicial, pode ter alcançado o estatuto de clítico.

Um argumento a favor dessa hipótese encontra-se na seção anterior e vamos retomálo aqui. Como vimos, no corpus de entrevistas sociolinguísticas (MOTA, 2011), foi identificado por Ramos (2011, p.79) a ocorrência de sô em posição argumental, desacompanhada de qualquer outro tipo de material. Para efeito de ilustração, repetimos os exemplos (27) e (28), abaixo:

(27) E as coisa que sô planta na roça sô traz para vender em Lontra? 
(28) De que matéria, sô sabe?

Exemplo (15) de Ramos (2011, p.79)

Em concordância com Moreira e Alkmim (2013) e Ramos (2011), consideramos que a posição à direita da oração, isoladamente como vocativo, é o locus do processo de pronominalização de senhor. Os exemplos (27) e (28) levam a crer que o uso de sô se expandiu para outro contexto sintático em que desempenha a função de sujeito e concorre com o pronome você: a posição de sujeito. A utilização de sô, neste contexto, oferece evidências de que, o seu estatuto gramatical, é o de pronome.

Considerando a ocorrência de sô à esquerda da oração, condicionada à precedência por uma partícula de chamamento indireto ou por uma interjeição, levantamos a hipótese de que este item esteja passando por um processo de cliticização. Ao que parece, a partícula de chamamento indireto ou interjeição funcionam como um hospedeiro do item sô. ${ }^{6}$

Levantamos a hipótese de que o item sô esteja passando por um processo de cliticização, tendo em vista que a sua realização, isoladamente como vocativo, à esquerda da oração, como visto anteriormente, é possível somente se houver a precedência de uma partícula de chamamento direto ou uma interjeição propriamente dita, como visto nos exemplos (24) e (25). Será interessante identificar quando teve início este processo, no entanto, esta questão vai além dos propósitos deste artigo e certamente, será explorada em trabalho futuro.

\section{Algumas considerações}

Neste estudo, buscamos identificar uma possível causa para a redução de senhor, no caso de corresponder sintaticamente a um vocativo, que ocasionou a emergência de formas

\footnotetext{
${ }^{6}$ De acordo com Vitral (2002, p.165), um clítico é um elemento átono e deve se escorar em algum outro termo ou ter um hospedeiro. A cliticização, portanto, deve ser vista como um processo diacrônico, previsto através de estágios discretos que deverão ser percorridos por cada processo específico de cliticização.
} 
reduzidas. Mais especificamente, investigamos a implementação de uma forma em particular, no dialeto mineiro, qual seja, sô.

Moreira e Alkmim (2013) correlacionaram a emergência de sô à mudança de ordem do vocativo na oração. São evidências a favor da correlação entre a gramaticalização de senhor e sua consequente redução, como vocativo, à direita da oração:

(i) Moreira (2008) verifica, em corpus constituído por peças de teatro escritas por autores brasileiros no século XIX e XX, que o vocativo representado lexicalmente pela expressão nominal de tratamento senhor ocorre com maior frequência do que aqueles compostos por um nome próprio, parentesco, vocativos profissionais e apelidos;

(ii) a confirmação de Ramos (2011) de que a posição de vocativo à direita é o locus do processo de "pronominalização" de "senhor".

Levando em conta estas afirmativas, levantamos a hipótese de que a posição de vocativo à esquerda da oração é o locus do processo de cliticização. Como visto nessa posição, a ocorrência da forma sô é condicionada à precedência de uma partícula de chamamento direto ou uma interjeição.

Ao questionarmos sobre o período de tempo em que forma sô emergiu, consideramos as seguintes informações:

no corpus de Moreira (2008), representativo do Português Brasileiro dos séculos XIX e XX, não são encontradas ocorrências de formas reduzidas;

(ii) Ramos (2011), utilizando o corpus de Batista (2008), observa a ocorrência de formas plenas e reduzidas de senhor, com função de vocativo, no século XXI;

(iii) no exemplo (5) na Introdução deste artigo, apresentamos uma ocorrência da forma sô em 1897, como vocativo, situado à direita da oração, em peça de Modesto de Paiva.

As informações acima levam a crer que a forma sô emergiu ao final do século XIX, no mesmo momento em que se registra a mudança de ordem do vocativo na oração do dialeto mineiro (MOREIRA, 2005) e do Português Brasileiro (MOREIRA, 2008). Vale ressaltar que a entrada do item sô no sistema linguístico se deu em posição de vocativo, à direita da oração. A nosso ver, nessa posição, é atribuído o estatuto de pronome a este item. Este uso se expandiu 
para outro ambiente sintático, qual seja, a posição de sujeito, conforme exemplos apresentados por Ramos (2011, p.79). Neste artigo, apresentamos outro tipo de construção contendo o item sô, aquelas em que este item ocorre à esquerda da oração precedido por uma interjeição ou partícula de chamamento indireto. Considerando este tipo de ocorrência, levantamos a hipótese de que o item sô, neste ambiente sintático, apresenta estatuto gramatical de clítico, à medida em que se apoia nos itens lexicais situados à sua esquerda.

Uma consideração a ser feita é a de outras mudanças parecem estar correlacionadas ao fato linguístico sobre o qual discorremos aqui. Oliveira (1996) registra a perda do traço de formalidade no tratamento com o interlocutor na primeira metade do século XIX. A perda do traço de formalidade propiciou o uso de senhor como pronome e não apenas com título honorífico. Por sua vez, Ramos (2000) observa que diferentes formas de tratamento vão atingindo as camadas populares e senhor apresenta um ponto em comum com você, a partir do século XIX. Decerto, estas mudanças favoreceram a mudança de ordem do vocativo na oração (MOREIRA, 2008) e a implementação de sô que ocorreram ao final desse mesmo século.

Após cumprir com o objetivo proposto neste artigo, levantamos uma hipótese acerca da cliticização de sô, como vocativo, à esquerda da oração. Em estudo futuro, pretendemos desenvolver uma pesquisa a este respeito.

\title{
Referências
}

\begin{abstract}
ALKMIM, Mônica Guieiro Ramalho. Negativas sentenciais no dialeto mineiro: uma abordagem variacionista 2001. 260f. Tese (Doutorado em Estudos Linguísticos: Linguística Teórica e Descritiva). Faculdade de Letras, Universidade Federal de Minas Gerais, Belo Horizonte.
\end{abstract}

BATISTA, Hadinei Ribeiro. Corpus de diálogos em balcão de atendimento de órgão público. Belo Horizonte, 2008 (Inédito).

BRAGA, Tancredo. Terra Ideal. Revista local em 3 atos. Manuscrito Acervo Clube Teatral A. Azevedo. Biblioteca da Universidade Federal de São João Del Rei, São João Del Rei, 1915.

HILL, Virginia. Vocatives: How syntax meets with pragmatics? Leiden: Brill, 2014. vol. 5. Series Empirical Approaches to Linguistic Theory.

LEHMAN, Chistian. Thoughts on grammaticalization. Munich: Lincom Europa, 1995. Disponível em: https://www.christianlehmann.eu/publ/ASSidUE09.pdf. 2002. Acesso em: 14 de jun. de 2018.

MOREIRA, Juliana Costa. Interjeições e invocações: a ordem dos constituintes exclamativos no Português Brasileiro. Revista de Estudos Linguísticos e Literários. № 58, Núm Esp. 2017, Salvador. p. 61-82.

MOREIRA, Juliana Costa. O vocativo na língua coloquial de Minas Gerais nos séculos XIX e XX: uma abordagem variacionista, 2005. 113f. Monografia (Bacharelado em Estudos Linguísticos). Instituto de Ciências Humanas e Sociais, Univeridade Federal de Ouro Preto, Mariana. 
MOREIRA, Juliana Costa. O vocativo no Português Brasileiro nos séculos XIX e XX: um estudo de mudança linguística. 2008. 108f. Dissertação (Mestrado em Estudos Linguísticos: Linguística Teórica e Descritiva). Faculdade de Letras, Universidade Federal de Minas Gerais, Belo Horizonte.

MOREIRA, Juliana Costa; ALKMIM, Mônica Guieiro Ramalho de. Preenchedores de vocativo em peças teatrais. In: RAMOS, Jânia Martins.; COELHO, Sueli Maria Português Brasileiro Dialetal: temas gramaticais. Campinas: Mercado das Letras, 2013.p.73-90.

MOTA, Maria Alice. Corpus constituído de 15 entrevistas sociolinguísticas do século XXI. Lontra, 2011. (Inédito).

MOURA, Líllian Mara de; RAMOS, Jania Martins. Redução fonológica do item senhor e seu estatuto gramatical. Monografia (Bacharelado em Estudos Linguísticos). 2004, 101f. Faculdade de Letras, Universidade Federal de Minas Gerais.

OLIVEIRA, Marilza de. Respostas assertivas e suas variações nas línguas românicas: o seu papel na aquisição. Tese (Doutorado em Estudos Linguísticos). 1996, 200f. Instituto de Estudos da Linguagem, Universidade Estadual de Campinas, Universidade Estadual de Campinas.

PAIVA, Modesto de. A onça. Revista local em 3 atos. Manuscrito do Acervo Clube Teatral A. Azevedo. Biblioteca da Universidade Federal de Minas Gerais, São João Del Rei,1897.

PAIVA, Modesto de. Mudança de Capital. Comédia em 1 ato. Manuscrito do Acervo do Clube Teatral Artur Azevedo. Biblioteca da Universidade Federal de São João Del Rei, São João Del Rei, 1893.

RAMOS, Jania Martins. De nome a pronome: um estudo sobre o item senhor. Caligrama: Belo Horizonte, v.16, n.2, p. 69-84, 2011.

RAMOS, Jania Martins. Uma fórmula de tratamento e seu percurso - o trajeto de senhor nos sistemas social e linguístico. Palestra, Universidade de São Paulo, São Paulo, 2000.

RESENDE, S.N.C. de. A virgem Mártir de Santarém. Drama em 4 atos. Manuscrito do Acervo do Clube Teatral A. Azevedo. Biblioteca da Universidade Federal de São João Del Rei, São João Del Rei 1870.

RESENDE, Silviano Nunes Carvalho de. A virgem Mártir de Santarém. Drama em 4 atos. Manuscrito Acervo do Clube Teatral A. Azevedo. Biblioteca da Universidade Federal de São João Del Rei, São João Del Rei, 1870

VITRAL, Lorenzo Teixeira. A interpolação de "se" e suas consequências para a Teoria da Cliticização. Revista da Abralin, vol.1 nº 2. P. 161-197, 2002.

WEINREICH, Uriel; LABOV, William; HERZOG, Marvin I. Fundamentos empíricos para uma teoria da mudança linguística. Tradição por Marcos Bagno; Revisão técnica por Carlos Alberto Faraco. São Paulo: Parábola, 2006. 